\title{
BEHAVIORAL OPERATIONS MANAGEMENT: A BLIND SPOT AND A RESEARCH PROGRAM
}

\author{
KONSTANTINOS V. KATSIKOPOULOS \\ Max Planck Institute for Human Development \\ GERD GIGERENZER \\ Max Planck Institute for Human Development \\ Harding Center for Risk Literacy
}

\begin{abstract}
Behavioral operations management, or simply behavioral operations (BOps), aims at understanding the decision-making of managers and at using this understanding to generate interventions that improve the operation of the supply chain. To do so, BOps imports knowledge from a number of fields such as economics, psychology and other social and behavioral sciences. We point out a blind spot in this knowledge: In BOps, the heuristics that people use are typically, although not always, viewed as a liability. The issue with this view is that it does not explain when and in what way heuristics can be an asset. We propose, as a research program for BOps, uncovering the conditions under which the heuristics that supply chain managers use are an asset, as well as the conditions under which they are a liability. We briefly discuss some research on heuristics in BOps and show how the study of quantitative models of heuristics can complement it.
\end{abstract}

Keywords: behavioral operations management; behavioral operations; behavioral supply management; human judgment and decision-making; heuristics; economics; conceptual theory development; modelling

\section{INTRODUCTION}

Managerial decision-making is of course very important in supply chains. The standard approach to understanding it assumes that managers are rational economists - they gather all relevant information and use all necessary time and computational resources to process this information - but the times are changing: Carter, Kaufmann and Michel (2007) introduced behavioral supply management, 'as the study of how judgment in supply management decision-making deviates from the assumptions of homo economicus' (p. 634). In this note, we use the term behavioral operations management or simply behavioral operations (BOps) (Gans \& Croson, 2008; Gino \& Pisano, 2008; Loch \& Wu, 2005).

Acknowledgments: We thank Craig Carter, Karen Donohue, Matthias Ehrgott, Lutz Kaufmann, Christoph Loch, Özgür Şimşek and three anonymous reviewers for their helpful comments on previous versions of this work.
Behavioral operations is an interdisciplinary endeavour (Bendoly, Croson, Goncalves \& Schultz, 2010; Carter et al., 2007; Gans \& Croson, 2008; Kaufmann, Carter \& Buhrmann, 2010; Kaufmann, Michel \& Carter, 2009; Loch \& Wu, 2005). Now, to paraphrase Alexander Pope, a little interdisciplinary learning is a dangerous thing: BOps has imported mainly one view of decision-making, in which the heuristics that people use, which lead to deviations from the assumptions of homo economicus, are typically viewed as a liability. We aim at making BOps researchers aware of a blind spot in this view: Heuristics can be an asset, and research outside BOps has identified conditions under which heuristics lead to better, or worse, decisions.

\section{HEURISTICS CAN BE AN ASSET}

There are many definitions of heuristics in computer science, psychology and operations research (for more discussion, see Katsikopoulos, 2011). In psychology, 
some researchers draw a distinction between intuitive and deliberate heuristics (Kahneman, 2003) and others question the usefulness of this distinction (Kruglanski \& Gigerenzer, 2011). In this note, a heuristic is defined as a simple rule of thumb that leads to decisions in little time and with little information and computation. For example, Simon's (1955) satisficing is a heuristic: Decision options are searched until an option with attribute values better than predetermined thresholds is found - for example, a coffee machine supplier who can deliver 1,000 machines within 2 weeks and charges $<\$ 50,000$ - when such an option is found, no more information is gathered, no more computations are made, and this option is chosen. Heuristics do not aim at finding an option that optimizes a mathematical model of the decision problem.

It is clear that managers use heuristics (March, 1994). The question is what to do about that. Should we try to change it, let it be or foster it? It depends on what research tells us about the performance of heuristics on the decision problem at hand. There are two major research programs on heuristic decision-making (Kelman, 2011), but just one seems to dominate the BOps literature.

In the work of Tversky and Kahneman and their colleagues, heuristics are linked to biases, in the sense of deviations from the norms of logic and probability. In fact, their research program is known as the heuristics-and-biases program (Kahneman, Slovic \& Tversky, 1982). BOps has picked this label up (Carter et al., 2007; Loch \& $\mathrm{Wu}, 2005)$. The label is significant because it could be read as suggesting that heuristics are a liability. The point is not that the heuristics-andbiases program holds that heuristics are a liability; to be sure, Tversky and Kahneman (1974, p. 1124)) wrote: 'heuristics are quite useful, but sometimes they lead to severe and systematic errors'. But as Lopes (1991, p. 65) has argued in detail, research on heuristics and biases has led to 'widely published claims that human judgment abilities are poor'.

In this vein, it seems that heuristics are typically viewed as a liability in the BOps literature. For example, the title of Carter et al. (2007) foundational article identifies behavioral supply management with the study of biases: 'Behavioral supply management: A taxonomy of judgment and decision-making biases'. In their review of behavioral experiments in supply chain management research, Croson and Donohue (2002) focus on cognitive limitations when discussing observed human behaviour. Table 1 of the review of Gino and Pisano (2008) is a catalogue of how heuristics can impair the operation of systems and processes. The journal Production and Operations Management has a department of behavioral operations that seeks to understand operations, 'by explicitly accounting for empirically observed human tendencies and influences, such as decision biases, cognitive limitations, individual preferences and social institutions'. (http://www.poms.org/journal/departments/).

In all these cases, there is no mention of how heuristics can improve the operation of supply chains. The point is not that BOps holds that heuristics are a liability; for example, Loch and Wu (2005, p. 42) wrote: 'in many situations, they [heuristics] are good first cut approximates when other information is insufficient'. The point is that the BOps literature has not examined in what way exactly heuristics can be an asset.

The fast-and-frugal-heuristics program of Gigerenzer and his colleagues articulates how heuristics can be an asset, by viewing them as adaptive (Gigerenzer, Hertwig \& Pachur, 2011). Adaptive heuristics lead to outcomes that ensure the viability and competitiveness of their users (Payne, Bettman \& Johnson, 1993). For example, a manager who has identified a coffee machine supplier who delivers the required number of machines in a timely fashion and at a reasonable price may ensure the competitiveness of a supply chain. While there are references to fast and frugal heuristics and their efficacy in behavioral strategy (Bingham \& Eisenhardt, 2011; Levinthal, 2011), we could not find such references in the BOps literature. Interestingly, however, Bendoly, Donohue and Schultz (2006, pp. 740-741) have suggested that BOps models should not necessarily assume that decision makers 'intend' to optimize but that they can 'react' adaptively, just as users of fast and frugal heuristics are purported to do.

Note that the heuristics-and-biases- and fast-and-frugal-heuristics programs do not differ, as it is sometimes said, in that the former claims that heuristics are mostly a liability while the latter claims that they are mostly an asset (see also the exchange between Kahneman \& Tversky, 1996 and Gigerenzer, 1996). Attempting to establish either claim would lead to the wrong research questions. The difference is that the fast-and-frugal-heuristics program has developed quantitative models of heuristics - instead of verbal labels such as availability - and used these models to identify precise conditions under which heuristics lead to better, or worse, decisions than models that use more time, information and computation. This is the study of the ecological rationality of heuristics (Todd \& Gigerenzer, 2012). This term expresses that the fastand-frugal-heuristics program evaluates heuristics not according to logical norms such as transitivity but according to performance in the ecology of real-world decision problems.

For example, consider the problem of predicting the purchasing behaviour of customers. It is important to know which of the past customers will continue buying (the active customers) and which will not (the inactive customers). Wuebben and von Wagenheim 
(2008) reported that, in the airline and apparel businesses, experienced managers rely on a fast and frugal heuristic, the hiatus heuristic: 'Call $t$ the number of months since a customer's last purchase. Classify the customer as active if and only if $t<9^{\prime}$.

It is tempting to assume that the hiatus heuristic leads to inferior performance. After all, it uses only one attribute (time since the last purchase) and ignores the full purchase history, which is used by traditionally rational models such as the Pareto-NBD (Negative-Binomial Distribution) model. Wuebben and von Wagenheim (2008), however, found that the heuristic model made more accurate predictions than the Pareto-NBD model in the airline and apparel businesses and that the models were equally accurate in the music business.

More generally, the study of ecological rationality has identified general conditions under which fast and frugal heuristics, such as the hiatus heuristic, perform well or less well (Katsikopoulos, 2011). For example, models of heuristics tend to perform better than more mathematically sophisticated models, developed in operations research and management science, when the sample available to calibrate parameters is small.

In the same spirit, we propose as a research program for BOps, uncovering the conditions under which the heuristics that supply chain managers use are an asset, as well as the conditions under which they are a liability.

Of course, there exists research on heuristics in BOps. The next section briefly discusses some of this research and shows how the study of fast and frugal heuristics can complement it.

\section{THE STUDY OF HEURISTICS}

Behavioral approaches to supply chain management seem to follow, to a large extent, on the footsteps of behavioral economics. This means that (i) data are gathered on people's actual decision-making, and (ii) the data are modelled by assuming that people decide as if they optimize a utility function. We believe that the study of fast and frugal heuristics can contribute on both counts.

First, consider BOps empirical research. Some of it seems to not try to identify the heuristics people use. For example, the work on the beer distribution game focuses on either demonstrating the so-called bullwhip effect - orders at each level of the supply chain oscillate and these oscillations amplify from downstream to upstream - or at reducing it (Croson \& Donohue, 2002). Identifying the heuristics at work would mean specifying the underlying psychological processes that lead to the effect. For example, based on Croson and Donohue (2002), a first speculation may be that upstream chain members, such as manufacturers, make decisions by considering information sequentially whereby the inventory position of the retailer is first in the sequence, and if this attribute is not known, they decide based on the next known attribute in the sequence (the complete sequence of attributes remains to be specified).

Identifying the underlying heuristic processes would increase our understanding of operational decisionmaking. It has been done outside BOps. For example, heuristics that rely on one attribute have helped to understand decisions in the laboratory as well as in the wild' (Gigerenzer et al., 2011). To wit, in order to decide which of two residential properties is more likely to be burgled, police officers and experienced burglars in the UK appear to use only one attribute (for example, is there a garden in the property? Garcia-Retamero \& Dhami, 2009).

Second, consider modelling in BOps. In behavioral economics, it is assumed that people decide as if they optimize a utility function. Beyond monetary self-interest, this utility function also captures social preferences and norms. For example, to describe equal-split offers in bargaining games, Fehr and Schmidt (1999) included inequity aversion in the utility function. In BOps, Loch and $\mathrm{Wu}$ (2008) used this approach to build a model of how a manager chooses a supplier. Another method of behavioral economics is to model people as not always making a utilitymaximizing decision but as potentially making any decision according to a probability distribution that depends on utilities. This can be done using the quantal response framework of McKelvey and Palfrey (1995). In BOps, Su (2008) built a newsvendor model by combining a utility function with the quantal response framework.

It has been questioned how well utility models describe human behaviour (Binmore \& Shaked, 2010; Friedman \& Sunder, 2011). This is a controversial point (see the exchange between Binmore \& Shaked, 2010 and Fehr \& Schmidt, 2010). Below, we argue for the weaker thesis that the descriptive adequacy of utility models has not yet been established, and thus alternative models, such as models of heuristics, should be considered as well.

If a model can fit a behaviour, this does not necessarily mean that it can also predict it. In prediction, the model parameters are calibrated on a data sample, and the model, with fixed parameters, is tested on another sample; in fitting, the parameters are calibrated anew on each sample. In other words, fitting refers to making sense of the past and prediction refers to forecasting the future. In the philosophy of science, prediction is considered to be a more appropriate test of how descriptively adequate a model is (Musgrave, 1974), and this is also accepted in behavioral economics (Fehr \& Schmidt, 2010). 
Thus, it is necessary to compare the predictive accuracy of competing models such as utility and heuristic models. This, unfortunately, is rarely done in behavioral economics (Binmore \& Shaked, 2010). We could not find such work in BOps either. Research outside BOps suggests that model comparisons in BOps cannot be just assumed to favour utility models. For example, in risky choice, it has been shown empirically and analytically (Katsikopoulos \& Gigerenzer, 2008) that the so-called priority heuristic - which considers attributes sequentially - has higher predictive accuracy than Tversky and Kahneman (1992) cumulative prospect theory. In ultimatum bargaining, a quantitative model of Tversky and Kahneman's anchoring-and-adjustment heuristic is more predictively accurate than the Fehr and Schmidt (1999) model combined with the quantal response framework (Hariskos, Katsikopoulos \& Gigerenzer, 2012).

In sum, given the contributions of the study of models of fast and frugal heuristics in research outside BOps, we suggest that it can be used to complement BOps research on heuristics.

\section{CONCLUSIONS}

Behavioral operations are an interdisciplinary endeavour. But so far it has incorporated primarily one view of how people make decisions, a view that automatically links people's heuristics to biases and errors. We addressed this blind spot by drawing attention to the fast-and-frugal-heuristics research program. This program has shown that quantitative models of heuristics can outperform models traditionally considered more rational. Work on the ecological rationality of heuristics provides an insight into the fact that when this is the case and when it is not. Quantitative models of heuristics have also been used to describe laypeople's and professionals' actual decision-making, in some cases better than utility models do. This note will have achieved its purpose if it raises the awareness of BOps researchers about the interesting ways in which the study of fast and frugal heuristics can influence theory development in the supply chain management discipline.

\section{REFERENCES}

Bendoly, E., Croson, R., Goncalves, P., \& Schultz, K. (2010). Bodies of knowledge for research in behavioral operations. Productions and Operations Management, 19(4), 434-452.

Bendoly, E., Donohue, K., \& Schultz, K. (2006). Behavioral operations management: Assessing recent findings and revisiting old assumptions. Journal of Operations Management, 24(6), 737752.
Bingham, C. B., \& Eisenhardt, K. M. (2011). Rational heuristics: The 'simple rules' that strategists learn from process experience. Strategic Management Journal, 32(13), 1437-1464.

Binmore, K., \& Shaked, A. (2010). Experimental economics: Where next? Journal of Economic Behavior and Organizations, 73, 87-100.

Carter, C. R., Kaufmann, L., \& Michel, A. (2007). Behavioral supply management: A taxonomy of judgment and decision-making biases. International Journal of Physical Distribution and Logistics Management, 37(8), 631-669.

Croson, R., \& Donohue, K. (2002). Experimental economics and supply chain management. Interfaces, 32(5), 74-82.

Fehr, E., \& Schmidt, K. (1999). A theory of fairness, competition, and cooperation. Quarterly Journal of Economics, 114, 817-868.

Fehr, E., \& Schmidt, K. (2010). On inequity aversion: A reply to Binmore and Skaked. Journal of Economic Behavior and Organizations, 73, 101-108.

Friedman, D., \& Sunder, S. (2011). Risky curves: From unobservable utility to observable opportunity sets. Working paper, New Haven, CT: Cowles Foundation for Research in Economics, Yale University.

Gans, N., \& Croson, R. (2008). Introduction to the special issue on behavioral operations. Manufacturing and Service Operations Management, 10(4), 563-565.

Garcia-Retamero, R., \& Dhami, M. K. (2009). Takethe-best in expert-novice decision strategies for residential burglary. Psychonomic Bulletin and Review, 16, 163-169.

Gigerenzer, G. (1996). On narrow norms and vague heuristics: A reply to Kahneman and Tversky. Psychological Review, 103(4), 592-596.

Gigerenzer, G., Hertwig, R., \& Pachur, T. (2011). Heuristics: The Foundations of Adaptive Behavior. New York, NY: Oxford University Press.

Gino, F., \& Pisano, G. (2008). Toward a theory of behavioral operations. Manufacturing and Service Operations Management, 10(4), 676-691.

Hariskos, W., Katsikopoulos, K. V., \& Gigerenzer, G. (2012). A quantitative model of the anchoring- andadjustment heuristic for the ultimatum game. Working paper. Germany: Center for Empirical Research in Economics and Behavioral Sciences, University of Erfurt.

Kahneman, D. (2003). A perspective on judgment and choice: Mapping bounded rationality. American Psychologist, 58, 697-720.

Kahneman, D., Slovic, P., \& Tversky, A. (1982). Judgment Under Uncertainty: Heuristics and Biases. Cambridge, UK: Cambridge University Press.

Kahneman, D., \& Tversky, A. (1996). On the reality of cognitive illusions: A reply to Gigerenzer's critique. Psychological Review, 103(4), 582-591.

Katsikopoulos, K. V. (2011). Psychological heuristics for making inferences: Definition, performance, and the emerging theory and practice. Decision Analysis, 8(1), 10-29. 
Katsikopoulos, K. V., \& Gigerenzer, G. (2008). Onereason decision-making: Modeling violations of expected utility theory. Journal of Risk and Uncertainty, 37(1), 35-56.

Kaufmann, L., Carter, C. R., \& Buhrmann, C. (2010). Debiasing the supplier selection decision: A taxonomy and conceptualization. International Journal of Physical Distribution and Logistics Management, 40(10), 792-821.

Kaufmann, L., Michel, A., \& Carter, C. R. (2009). Debiasing strategies in supply management decision making. Journal of Business Logistics, 30(1), 85 -106 .

Kelman, M. G. (2011). The Heuristics Debate. New York, NY: Oxford University Press.

Kruglanski, A. W., \& Gigerenzer, G. (2011). Intuitive and deliberate judgments are based on common principles. Psychological Review, 118(1), 97-109.

Levinthal, D. A. (2011). A behavioral approach to strategy-What's the alternative? Strategic Management Journal, 32(13), 1517-1523.

Loch, C., \& Wu, Y. (2005). Behavioral operations management. Foundations and Trends in Technology, Information, and Operations Management, 1(3), 121-232.

Loch, C., \& Wu, Y. (2008). Social preferences and supply chain performance: An experimental study. Management Science, 54(11), 1835-1849.

Lopes, L. L. (1991). The rhetoric of irrationality. Theory and Psychology, 1(1), 65-82.

March, J. G. (1994). A Primer on Decision Making: How Decisions Happen. New York, NY: Free Press.

McKelvey, R. D., \& Palfrey, T. R. (1995). Quantal response equilibria for normal-form games. Games and Economic Behavior, 7, 6-38.

Musgrave, A. (1974). Logical versus historical theories of confirmation. British Journal of Philosophy of Science, 25, 1-23.

Payne, J. W., Bettman, J. R., \& Johnson, E. J. (1993). The Adaptive Decision Maker. Cambridge, UK: Cambridge University Press.

Simon, H. A. (1955) A behavioral model of rational choice. Quarterly Journal of Economics, 69(1), 99118.

$\mathrm{Su}$, X. (2008). Bounded rationality in newsvendor models. Manufacturing and Service Operations Management, 10(4), 566-589.

Todd, P. M., Gigerenzer, G., \& the ABC Research Group (2012). Ecological Rationality: Intelligence in the World. New York: Oxford University Press.

Tversky, A., \& Kahneman, D. (1974). Judgment under uncertainty: Heuristics and biases. Science, 185 (4157), 1124-1131.

Tversky, A., \& Kahneman, D. (1992). Advances in Prospect Theory: Cumulative Representation of Uncertaint. Journal of Risk and Uncertainty, 5(4), 297-323.
Wuebben, M., \& von Wagenheim, F. (2008). Instant customer base analysis: Managerial heuristics often "get it right". Journal of Marketing, 72, 82-93.

Konstantinos V. Katsikopoulos (Ph.D., University of Massachusetts-Amherst) is a senior research scientist in the Center for Adaptive Behavior and Cognition at the Max Planck Institute for Human Development in Berlin, Germany. His research focuses on understanding how people learn, reason and make judgments/decisions; towards that end, he uses tools and concepts developed by disciplines including operations research, psychology, economics and systems engineering. Dr. Katsikopoulos' current research projects involve collaborative efforts with the WHU-Otto Beisheim School of Management to determine how supply chain managers use intuition in decisionmaking, and with the Bank of England to develop decision trees to determine financial risk and communicate those risks internally and with the public. His research has been published in many academic journals including the Journal of Mathematical Psychology, Decision Analysis, Psychological Review and Cognitive Science.

Gerd Gigerenzer (Ph.D., Ludwig Maximilians University) is the Director of the Center for Adaptive Behavior and Cognition at the Max Planck Institute for Human Development, and also of the Harding Center for Risk Literacy, in Berlin, Germany. His research interests include bounded rationality and social intelligence, decision-making under uncertainty and time constraints, competence in risk and risk communication, and the decision-making strategies used by professionals such as judges, managers and physicians. Dr. Gigerenzer has published several books including Heuristics (2011), Rationality for Mortals (2008), Calculated Risks (2002) and Bounded Rationality (2001, with Reinhard Selten). He is the recipient of many prestigious awards, including the American Association for the Advancement of Science Prize for Behavioral Science Research. 